Article

\title{
A DFT Study for Catalytic Deoxygenation of Methyl Butyrate on a Lewis Acid Site of ZSM-5 Zeolite
}

\author{
Xiaobo Chen, Ruiying Li, Hao Yan, Yibin Liu * (i) and Chaohe Yang \\ State Key Laboratory of Heavy Oil Processing, China University of Petroleum, Qingdao 266580, China; \\ chenxiaobo@upc.edu.cn (X.C.); B20030009@s.upc.edu.cn (R.L.); haoyan@upc.edu.cn (H.Y.); \\ yangch@upc.edu.cn (C.Y.) \\ * Correspondence: liuyibin@upc.edu.cn; Tel.: +86-532-86980917
}

Received: 7 October 2020; Accepted: 22 October 2020; Published: 24 October 2020

\begin{abstract}
The catalytic deoxygenation mechanism of fatty acid esters on a Lewis acid site of ZSM-5 zeolite was elucidated via density functional theory (DFT) by using a methyl butyrate (MB) as the model compound for fatty acid esters. The configurations of the initial reactant, transition states, and products together with the activation barrier of each elementary reaction were determined. The activation barrier of different initial cracking reactions decreases in the order of $\alpha-\mathrm{C}-\mathrm{C}>\beta-\mathrm{C}-\mathrm{C}>\alpha-\mathrm{C}-\mathrm{O}>\beta-\mathrm{C}-\mathrm{O}$. The best reaction path for catalytic deoxygenation of methyl butyrate over Lewis acid site is $\mathrm{CH}_{3} \mathrm{CH}_{2} \mathrm{CH}_{2} \mathrm{C}\left(\mathrm{OCH}_{3}\right)=\mathrm{O} \cdots$ Lewis $\rightarrow \mathrm{CH}_{3} \mathrm{CH}_{2} \cdots$ Lewis $\cdots \mathrm{C}\left(=\mathrm{CH}_{2}\right) \mathrm{OCH}_{3} \rightarrow$ $\mathrm{CH}_{2}=\mathrm{CH}_{2}+\mathrm{CH}_{3} \mathrm{COOCH}_{3}+$ Lewis. The oxygen of methyl butyrate is mainly removed as $\mathrm{CO}_{2}$, methyl acetate, formaldehyde, and butyraldehyde, while ethylene, propylene, and butane are the main hydrocarbon products. In addition, the group generated by cracking of methyl butyrate form a bond with the Lewis acid site, promoting the transformation between a Lewis acid and a Brønsted acid. The corresponding intermediates have a high single point energy, but the poor stability leads to further deoxygenation and cracking reactions. This work provides a theoretical basis for the modification in the number of Brønsted acid and Lewis acid sites in the ZSM-5 zeolite.
\end{abstract}

Keywords: deoxygenation mechanism; methyl butyrate; Lewis acid; ZSM-5; DFT

\section{Introduction}

The efficient utilization of fatty acid esters is of great significance to alleviate the shortage of fossil resources. The processes currently include transesterification, thermal cracking, catalytic hydrogenation, and catalytic cracking [1-3]. Compared with other processes, the catalytic cracking has attracted more attention because of the advantages of low production cost and simple process. ZSM-5 zeolite catalyst with unique pore structures and good aromatization activity, which show a good performance in the catalytic cracking of fossil feedstocks, are introduced into the catalytic cracking of fatty acid esters [4-7]. The catalytic cracking product over ZSM-5 zeolite catalysts had higher organic liquid yield and aromatic hydrocarbon selectivity compared with other catalysts. However, the liquid product is less stable because it contains an abundance of small molecular oxygenates. Hence, designing a reasonable catalyst for catalytic cracking of fatty acid esters to reduce the oxygen content in the liquid product is particularly important.

It has become a new research thinking to provide a theoretical basis for catalyst design through mechanism research. Some researchers have inferred the catalytic cracking mechanism of fatty acid esters and carboxylic acids. Phung et al. [8] investigated the catalytic conversion of acetic acid on faujasite zeolites (NaX, USY, and HY) by in-situ infrared analysis, and inferred the possible reaction steps. Cai et al. [9] revealed a possible reaction pathway of octanoic acid methyl ester over USY zeolite catalyst. Botas et al. [10] also proposed a reaction pathway for vegetable oil over ZSM-5 zeolite. 
Li et al. [11] investigated the deoxygenation mechanism of fatty acid esters on a Brønsted acid site of HZSM-5 using a methyl butyrate as a model compound by DFT calculation. Yan et al. [12] also studied the catalytic cracking mechanism of acetic acid as a model compound of bio-oil using the similar method. However, there are two kind of acid sites in zeolites, Brønsted acid and Lewis acid. The products catalyzed by different acid sites are different, meaning that the reaction mechanism is different on Brønsted acid and Lewis acid. To the best of our knowledge, there are no reports on the deoxygenation mechanism of fatty acid esters on a Lewis acid site of zeolite. Some studies over $\mathrm{Al}_{2} \mathrm{O}_{3}$, which is usually used as a Lewis acid catalyst, have been reported. Vonghia et al. [13] explored the deoxygenation mechanism of vegetable oils on an $\mathrm{Al}_{2} \mathrm{O}_{3}$ catalyst. The result shows that triglycerides can generate carboxylic acids and olefins through $\beta$-elimination. Then, two carboxylic acids form a ketone, $\mathrm{CO}_{2}$, and $\mathrm{H}_{2} \mathrm{O}$. Experimental studies of catalytic conversion of several carboxylic acids conducted by Leung et al. also confirmed this conclusion [14]. Phung et al. [15] also inferred the catalytic cracking mechanism of ethyl acetate and acetic acid on alumina by in-situ infrared analysis. The abovementioned studies presented that the $\mathrm{CO}_{2}$ is the main deoxygenation product over alumina. To sum up, the research on the catalytic reaction mechanism of fatty acid ester over Lewis acid is still at the experimental stage.

As a new research method, density functional theory (DFT) calculation has been widely used to study catalytic reaction mechanisms. It can provide the knowledge of adsorption configuration, energy barriers, transition state, etc. [16-23]. Many researchers have successfully introduced DFT to elucidate the catalytic reaction mechanism of oxygen-containing compounds. DFT has been used to investigate the thermal cracking of methyl butyrate $[24,25]$, the deoxygenation mechanism on a Brønsted acid of HZSM-5 [11], and the catalytic cracking of acetic acid on HZSM-5 zeolite [12]. Moreover, Chukwu et al. [26] revealed the decarboxylation reaction pathways and decarbonylation reaction pathways for decomposition of acetic acid on Pd(111) by DFT. Banerjee et al. [27] used furfural as a model compound of bio-oil to study the deoxygenation pathways by DFT calculation. Therefore, the DFT method is a reasonable and feasible approach to the study of the reaction mechanisms.

In this work, we introduced DFT to study catalytic reaction mechanism of fatty acid ester over a Lewis acid of ZSM-5 zeolite. Methyl butyrate was used as the model compound, and the seven reaction paths were designed according to different preliminary cracking reactions (cracking of the $\alpha-C-C$ bond, $\beta-\mathrm{C}-\mathrm{C}$ bond, $\alpha-\mathrm{C}-\mathrm{O}$ bond, and $\beta-\mathrm{C}-\mathrm{O}$ bond). The activation barrier and transition state configuration of different reaction paths were determined through searching transition state. The reason for the high $\mathrm{CO}_{2}$ yield under Lewis acid catalysis was explained. The results provide a specific theoretical basis for modification of acid type of zeolite to get high purity target product.

\section{Results and Discussion}

\subsection{Adsorption of Methyl Butyrate}

Figure 1 shows the optimized structure of a methyl butyrate molecule adsorbed on the Lewis acid of ZSM-5 zeolite. Compared with the Lewis acid model, it was found that the $\mathrm{Al}$ atom detached from the plane shared with three oxygen atoms. The data before and after adsorption in Table 1 prove the correctness of this conclusion. The distance between the carbonyl oxygen and the $\mathrm{Al}$ atom was shortened to $1.862 \AA$, which is in accordance with the ordinary distance of Al-O bond $\left(1.70 \AA \sim 1.90 \AA\right.$ ) [28]. The carbonyl bond also increased slightly, and the distance between the $C_{4}$ and $\mathrm{O}_{1}$ increased from $1.207 \AA$ to $1.236 \AA$. In addition, the positive charge of $\mathrm{Al}$ atom increases and the negative charge of $\mathrm{O}_{1}$ atom decreases. It shows that a part of the charge in the $32 \mathrm{~T}$ cluster model is gradually transferred to the $\mathrm{MB}$ molecule through $\mathrm{A}_{1}$ and $\mathrm{O}_{1}$ atom after adsorption. The change of structural parameters and the transfer of Mulliken charge both indicate the formation of $\mathrm{Al}-\mathrm{O}$ bond, and the tri-coordination aluminum is gradually transformed into a tetra-coordination structure. 


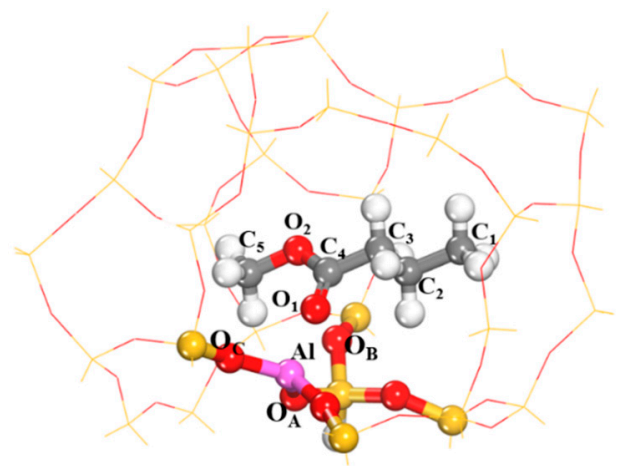

Figure 1. Adsorption structure of a methyl butyrate (MB) on the Lewis acid of ZSM-5 zeolite.

Table 1. Geometry parameters and Mulliken charge of MB before and after adsorption.

\begin{tabular}{|c|c|c|c|c|c|c|c|c|c|c|}
\hline \multirow{2}{*}{ MB } & \multicolumn{2}{|c|}{ Distance (Å) } & \multicolumn{3}{|c|}{ Angle ( $\left.{ }^{\circ}\right)$} & \multicolumn{5}{|c|}{ Charge (e) } \\
\hline & $\mathrm{O}_{1}-\mathrm{C}_{4}$ & $\mathrm{O}_{1}-\mathrm{Al}$ & $\angle \mathbf{O}_{\mathrm{A}}-\mathrm{Al}-\mathrm{O}_{\mathrm{B}}$ & $\angle \mathbf{O}_{\mathrm{B}}-\mathrm{Al}-\mathrm{O}_{\mathrm{C}}$ & $\angle \mathrm{O}_{\mathrm{A}}-\mathrm{Al}-\mathrm{O}_{\mathrm{C}}$ & $\mathbf{O}_{\mathrm{A}}$ & $\mathrm{O}_{\mathrm{B}}$ & $\mathbf{O}_{\mathrm{C}}$ & Al & $\mathrm{O}_{1}$ \\
\hline $\begin{array}{c}\text { Before } \\
\text { adsorption }\end{array}$ & 1.207 & - & 119.926 & 120.46 & 119.478 & -0.588 & -0.612 & -0.587 & 0.998 & -0.920 \\
\hline $\begin{array}{c}\text { After } \\
\text { adsorption }\end{array}$ & 1.236 & 1.862 & 114.435 & 114.761 & 116.883 & -1.041 & -1.022 & -1.031 & 1.727 & -0.663 \\
\hline
\end{tabular}

\subsection{Deoxygenation Reaction Pathways}

The elementary reaction steps investigated for the catalytic deoxygenation of MB over a Lewis acid are shown in Figure 2. A methyl butyrate (MB) generates a methyl acetate and an ethylene by the $\beta-C-C$ bond cleavage (path I and path II). One of the reaction paths is that the $\beta-C-C$ bond breaks first (L-R1), followed by the hydrogen transfer reaction (L-R2). The other is that $\beta-C-C$ bond cleavage and hydrogen transfer occur simultaneously (L-R3). Cleavage of $\alpha-C-C$ bond may also have two paths. The first path is to generate a methyl formate and a propylene intermediates, then the methyl formate undergoes further decarbonylation reaction to form a methoxy (path III). The second path is to break the $\alpha-C-C$ bond first, and then the initial cracking product undergoes further cracking to generate a $\mathrm{CO}_{2}$ and a butane (path IV). Two cracking paths (path V and path VI) can be obtained through the $\alpha-\mathrm{C}-\mathrm{O}$ bond cleavage, resulting in the formation of formaldehyde and butyraldehyde, or methanol and butenone. In path VII, the $\beta-\mathrm{C}-\mathrm{O}$ bond is broken to form a methyl ion and a butyrate ion, both of which form bonds with oxygen and aluminum atoms on the zeolite. The butyric acid group further undergoes decarboxylation reaction to form alkyl molecules.

\subsubsection{Cracking of $\beta-C-C$ Bond}

The detailed structures of the reactants, transition states, products are shown in Figure 3. The L-R1 reaction passes through the transition state TS1 to generate the intermediate Int1. During the reaction L-R1, the $C_{2}-C_{3}$ bond is broken. The distance between the $C_{2}$ and $C_{3}$ atoms increases from $1.517 \AA$ to $3.133 \AA$, and the distance of $\mathrm{O}_{1} \cdots \mathrm{A}_{1}$ reduces from $1.862 \AA$ to $1.727 \AA$. The formed ethyl carbocation gradually gets close to the zeolite, corresponding to a decrease in the distance between the $C_{2}$ atom and the framework oxygen atom (from $3.439 \AA$ to $1.536 \AA$ ). It can be obtained from the structure diagram of Int1 in Figure 3 that the Lewis acid in the zeolite changes to a Brønsted acid. The $\mathrm{O}_{1}$ atom forms a new tetrahedral structure with the framework aluminum. The ethyl carbocation balances the charge of the zeolite to keep the reaction system electrically neutral. Liang et al. [29] also found that the skeleton aluminum atom can change from tri-coordination to tetra-coordination with the catalytic cracking of propylene oxide on a Lewis acid. The intermediate Int1 readily undergoes a hydrogen transfer reaction. The hydrogen atom at $C_{1}$ transfers to the $C_{3}$. Then, the $C_{2}$ dissociates from the oxygen atom of the framework to finally form ethylene and methyl acetate. 

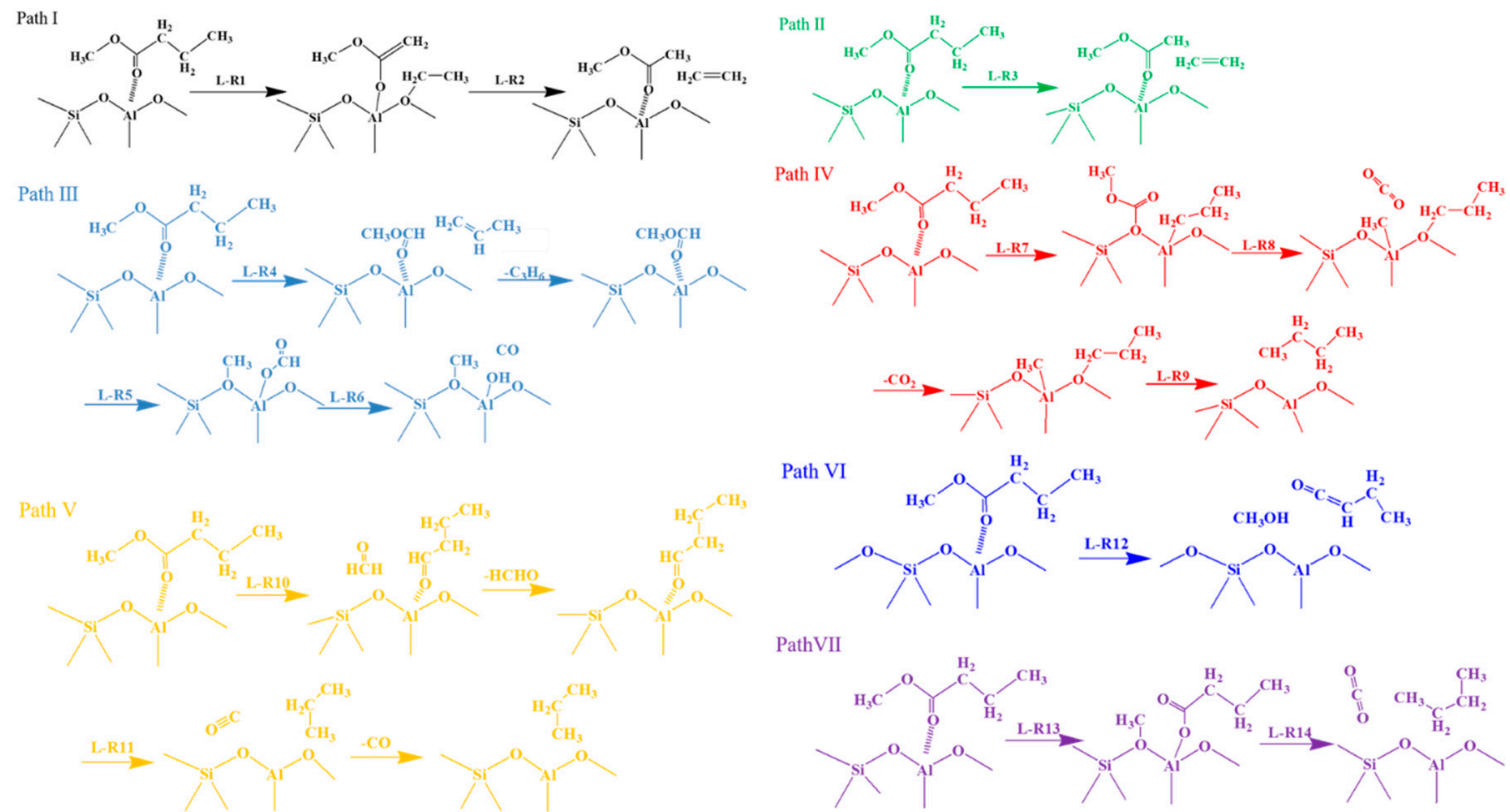

Figure 2. Deoxygenation reaction paths of MB on the Lewis acid of ZSM-5 zeolite.

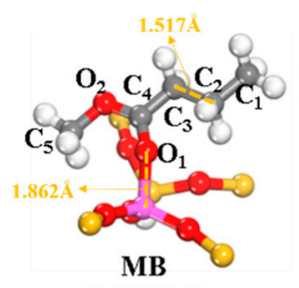

L-ZSM-5

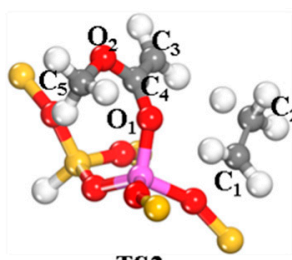

TS2

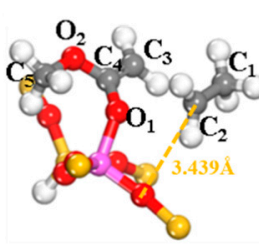

TS1

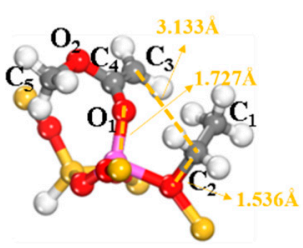

Int1

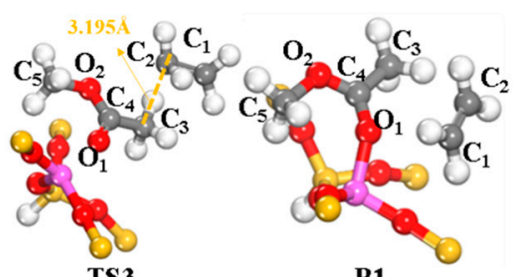

P1

Figure 3. The structures of initial, transition, and final states for the $\beta-\mathrm{C}-\mathrm{C}$ bond cleavage of $\mathrm{MB}$ on 32 T cluster of ZSM-5.

In path II, product is directly formed through the transition state TS2. The $\mathrm{C}_{2}-\mathrm{C}_{3}$ bond is stretched from $1.517 \AA$ to $3.195 \AA$, meaning the cleavage of $C_{2}-C_{3}$ bond. Simultaneously, the hydrogen atom at $C_{2}$ transfers to $C_{3}$ by a triangular transition state structure of $C \cdots H \cdots C$. This structure was also mentioned in the intermolecular hydrogen transfer reaction [30]. It is believed that the C $\cdots \mathrm{H} \cdots \mathrm{C}$ intermediate species are formed when alkylcarbenium ions take hydrogen atoms of alkanes.

\subsubsection{Cracking of $\alpha-\mathrm{C}-\mathrm{C}$ Bond}

Figure 4 presents the configurations of reactant, transition state and product of each elementary reaction for cleavage of $\alpha-C-C$ bond. In path III, a methyl butyrate is cracked at the $\alpha-C-C$ bond to form methyl formate and propylene by transition state TS4. The distance between $C_{3}$ and $C_{4}$ increases from $1.479 \AA$ to $2.408 \AA$, while the distance of $\mathrm{H} \cdots \mathrm{C}_{4}$ shortens from $2.076 \AA$ to $1.210 \AA$. Thus, one hydrogen atom on the $C_{3}$ transfers to the $C_{4}$ atom to form a stable methyl formate intermediate species. Then, the hydrogen atom on $C_{2}$ in the propyl carbocation transfers to the $C_{3}$. The corresponding distance of $\mathrm{H} \cdots \mathrm{C}_{2}$ increases from $1.097 \AA$ to $2.110 \AA$, while the distance of $\mathrm{H} \cdots \mathrm{C}_{3}$ shortens from $2.187 \AA$ to $1.084 \AA$. Finally, a stable propylene intermediate is formed, which makes the reaction system stable in terms of 
structure and charge population. The methyl formate formed from the initial cracking continues to undergo a deoxygenation reaction. The distance of $\mathrm{C}_{5} \cdots \mathrm{O}_{2}$ increases from $1.461 \AA$ to $2.358 \AA$, resulting in the cleavage of $\mathrm{C}_{5}-\mathrm{O}_{2}$ bond, and the distance of $\mathrm{C}_{5} \cdots$ O decreases from $2.314 \AA$ to $1.483 \AA$. $-\mathrm{CH}_{3}$ and $\mathrm{O}-\mathrm{CH}(=\mathrm{O})$ groups form bonds with the $\mathrm{Al}$ atom and $\mathrm{O}$ atom of the framework, respectively. It appears that the distance between the $\mathrm{O}_{1}$ atom and $\mathrm{Al}$ atom also decreases from $1.815 \AA$ to $1.771 \AA$. Immediately, the intermediate species Int 3 is cleaved to $\mathrm{CO}$ and a terminal hydroxyl saturated Brønsted acid through the transition state TS6. The $\mathrm{C}_{4}-\mathrm{O}_{1}$ bond is broken, and the distance between the two atoms increases from $1.318 \AA$ to $1.939 \AA$. In addition, the $\mathrm{H}$ atom on the $\mathrm{C}_{4}$ atom transfers to the $\mathrm{O}_{1}$ atom, forming a hydroxyl group for aluminum terminal saturation.

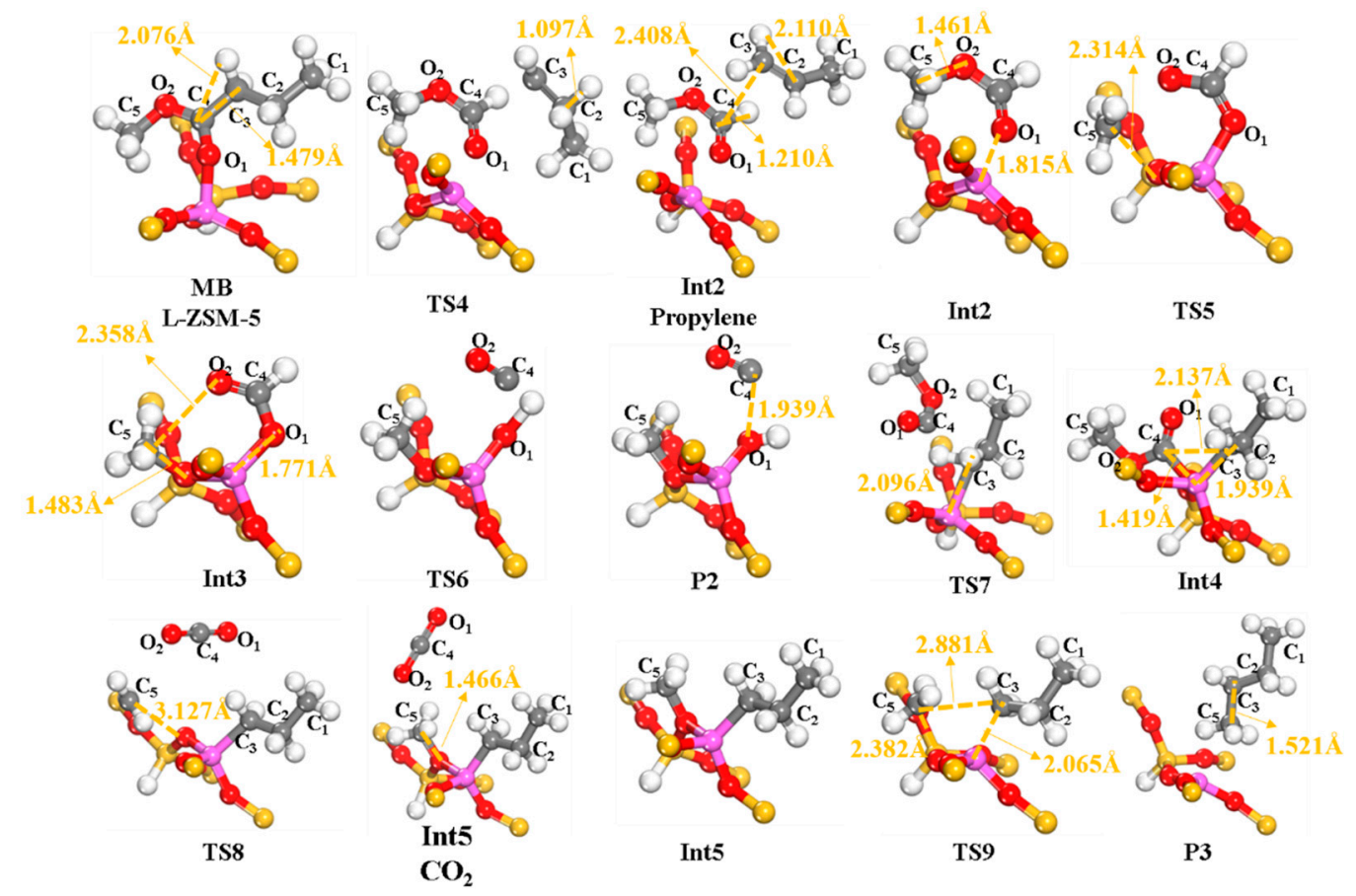

Figure 4. The structures of initial, transition, and final states for the $\alpha-C-C$ bond cleavage of MB on 32 T cluster of ZSM-5.

A methyl butyrate can be cleaved at the $\alpha-\mathrm{C}-\mathrm{C}$ bond to form propyl carbocation and ester ion via the transition state TS6 (path IV). The $\mathrm{C}_{3}-\mathrm{C}_{4}$ bond length increases from $1.479 \AA$ to $2.137 \AA$. As shown in the structure of Int 4 in Figure 4 , the length of $C_{3} \cdots A l$ shortens from $2.096 \AA$ to $1.939 \AA$, and the length of $\mathrm{C}_{4} \cdots$ O shortens to $1.419 \AA$, meaning the formation of $\mathrm{Al}-\mathrm{C}$ and $\mathrm{C}-\mathrm{O}$ bonds, resulting in the transformation of Lewis acid to Brønsted acid. The ester ion undergoes a decarboxylation reaction to generate $\mathrm{CO}_{2}$ and methoxide through transition state TS7. The methyl carbocation has a flat triangular structure in the transition state. Numerous studies have shown that carbocation cannot stably exist in the zeolite channels [31,32]. Therefore, the methyl carbocation gradually approaches the framework oxygen in the zeolite channel. The length of $\mathrm{C}_{5} \cdots \mathrm{O}$ shortens from $3.127 \AA$ to $1.466 \AA$ to form a $\mathrm{C}-\mathrm{O}$ bond. In the next reaction, two alkyl groups detach from the zeolite framework and recombine to form a $\mathrm{C}-\mathrm{C}$ bond. The distance between $\mathrm{C}_{5}$ and $\mathrm{O}$ atoms increases to $2.382 \AA$ and the distance of $\mathrm{C}_{3} \cdots \mathrm{Al}$ increases to $2.065 \AA$. Then, the $\mathrm{C}_{5}$ atom and $\mathrm{C}_{3}$ atom gradually approaches, and the distance between the two atoms decreases from $2.881 \AA$ to $1.521 \AA$. Finally, the methyl carbocation and the propyl carbocation bond to form a butane molecule.

\subsubsection{Cracking of $\alpha-\mathrm{C}-\mathrm{O}$ Bond}

According to the different combinations of atoms, there are two cracking paths when $\alpha-\mathrm{C}-\mathrm{O}$ bond is broken (path V and path VI), with the formation of formaldehyde and butyraldehyde, or methanol 
and butenone. It is derived from the structures of Figure 5 that during the path $\mathrm{V}, \mathrm{C}_{4}-\mathrm{O}_{2}$ bond is stretched to $2.589 \AA$. A hydrogen atom at the $\mathrm{C}_{5}$ atom transfers to the $\mathrm{C}_{4}$ atom. The distance of $\mathrm{H} \cdots \mathrm{C}_{4}$ decreases from $2.657 \AA$ to $1.098 \AA$ through the transition state TS10 $(2.322 \AA)$, and the distance of $\mathrm{H} \cdots \mathrm{C}_{5}$ gradually increases from $1.085 \AA$ to $1.264 \AA$. This change causes the breakage of the $\mathrm{H}-\mathrm{C}_{5}$ bond and the formation of the $\mathrm{H}-\mathrm{C}_{4}$ bond. Eventually, butyraldehyde and formaldehyde intermediate species are generated. Then, the butyraldehyde molecule adsorbed on the Lewis acid site continues to undergo cracking reactions. The length of $\mathrm{C}_{3}-\mathrm{C}_{4}$ bond increases to $2.005 \AA$, and the hydrogen atom on $\mathrm{C}_{4}$ atom gradually transfers to $\mathrm{C}_{3}$ atom to form a stable propane molecule. $\mathrm{O}_{2}$ atom and $\mathrm{C}_{4}$ atom are separated from the aluminum atom to form a CO molecule (as shown in the P4 structure diagram in Figure 5). The Lewis acid of the zeolite restores the original planar triangular structure.
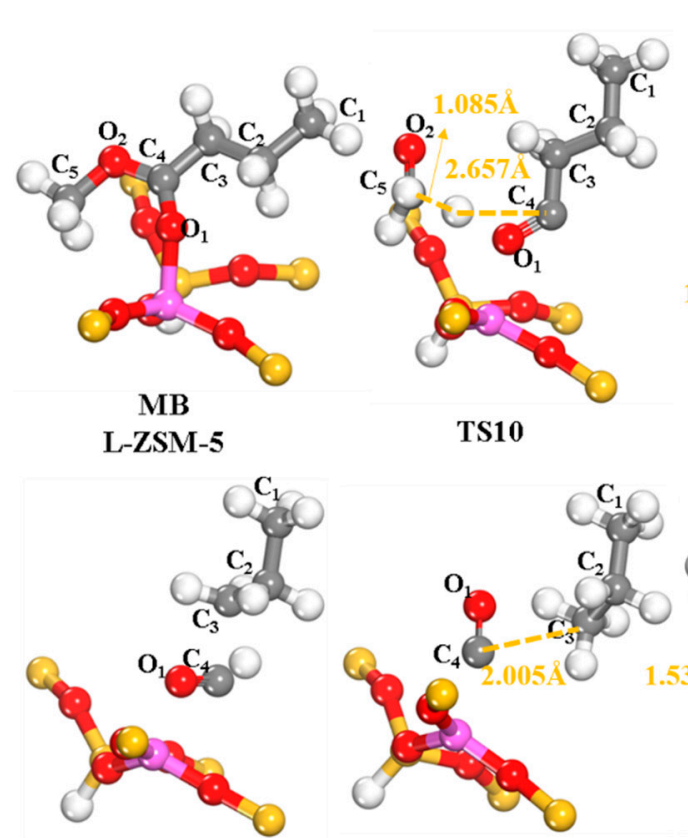

TS11

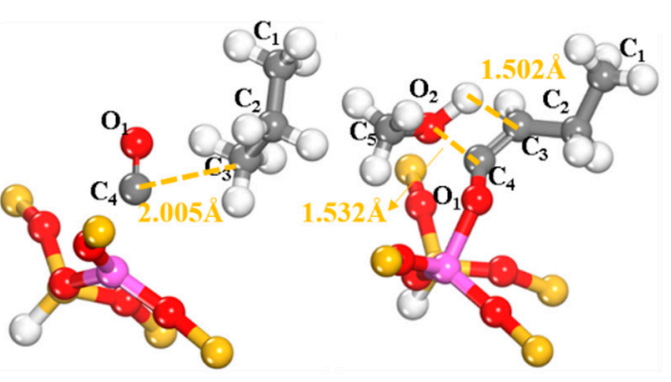

P4



HCHO

TS12
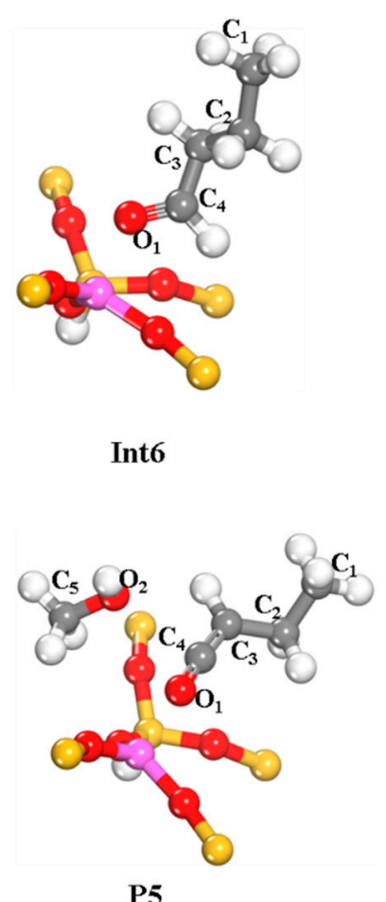

P5

Figure 5. The structures of initial, transition, and final states for the $\alpha-\mathrm{C}-\mathrm{O}$ bond cleavage of $\mathrm{MB}$ on 32 T cluster of ZSM-5.

In the path VI, the length of $\mathrm{C}_{4}-\mathrm{O}_{2}$ bond increases from $1.305 \AA$ to $1.532 \AA$. The distance of $\mathrm{C}_{3} \cdots \mathrm{H}$ increases from $1.090 \AA$ to $1.502 \AA$, and the distance of $\mathrm{O}_{2} \cdots \mathrm{H}$ shortens from $2.549 \AA$ to $0.962 \AA$ through the transition state TS12 (1.239 $\AA$ ). This observation means that a hydrogen atom on $\mathrm{C}_{3}$ atom transfers to $\mathrm{O}_{2}$ atom, and methanol is generated. Afterwards, $\mathrm{O}_{1}-\mathrm{C}_{4}$ bond deflects until the $\mathrm{C}_{3}$ atom remains in the same straight line to form a butenone molecule. This conclusion is in consistent with the result of infrared exploration experiment. In the in-situ infrared research experiment, it was also found that the formation of the butenone intermediate species in the reaction of ethyl acetate catalyzed by alumina. It was also found that ethyl acetate produces intermediate species of an alcohol and an enone on the alumina catalyst [15].

\subsubsection{Cracking of $\beta-\mathrm{C}-\mathrm{O}$ Bond}

As shown in the structural diagram of the transition state TS13 in Figure 6, the distance of $C_{5} \cdots O_{2}$ gradually increases from $1.457 \AA$ to $3.344 \AA$ during the cracking of $\beta-\mathrm{C}-\mathrm{O}$ bond. The generated $\mathrm{CH}_{3}$ group and $\mathrm{CH}_{3} \mathrm{CH}_{2} \mathrm{CH}_{2} \mathrm{C}(=\mathrm{O}) \mathrm{O}$ group get close to the oxygen and aluminum on the zeolite, respectively. The distance of $\mathrm{C}_{5} \cdots \mathrm{O}$ shortens to $2.480 \AA$ through the transition state to form a new $\mathrm{C}-\mathrm{O}$ bond. Additionally, the $\mathrm{O}_{1}$ atom and the $\mathrm{Al}$ atom form an Al-O bond. Similar to the reactions of L-R1 and L-R7, the Lewis acid transforms to a Brønsted acid after the reaction. Then, the butyrate group 
occurs the decarboxylation reaction via the transition state TS14. The $\mathrm{C}_{3}-\mathrm{C}_{4}$ bond is gradually extended from $1.498 \AA$ to $3.087 \AA$. The $\mathrm{O}_{1}$ estranges from $\mathrm{Al}$ to form a $\mathrm{CO}_{2}$ molecule. Simultaneously, the methyl group detaches from the zeolite, and then combines with the formed propyl group. The distance between $C_{5}$ and $C_{3}$ atoms reduces from $6.272 \AA$ to $1.520 \AA$ to form a stable butane molecule.

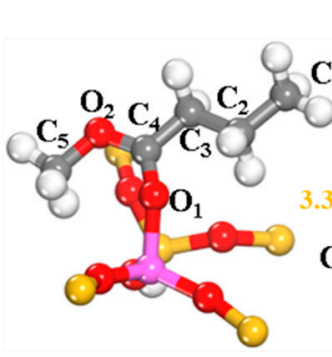

MB

L-ZSM-5

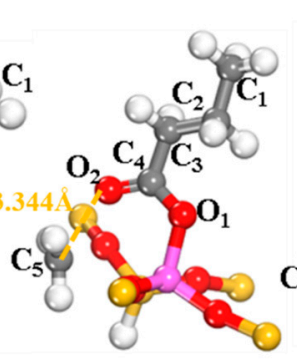

TS13

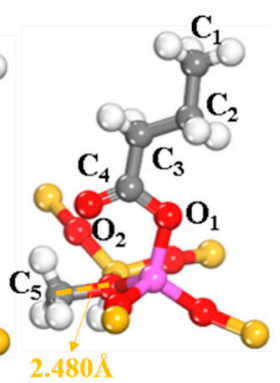

Int7

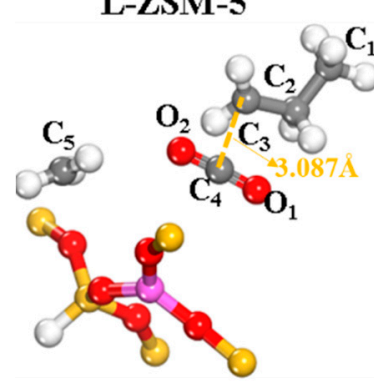

TS14

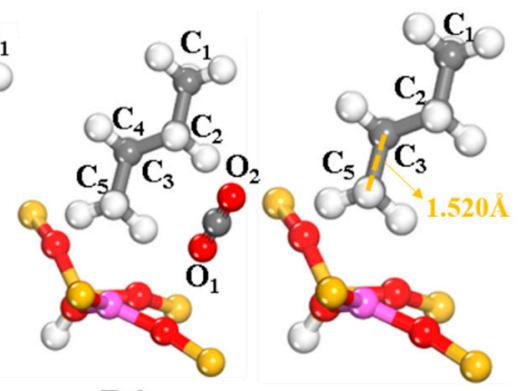

P6 $\mathrm{CO}_{2}$
P6

Figure 6. The structures of initial, transition, and final states for the $\beta-\mathrm{C}-\mathrm{O}$ bond cleavage of $\mathrm{MB}$ on 32 T cluster of ZSM-5.

\subsection{Activation Energy}

The potential energy diagram of the path I-path VII is shown in Figure 7.

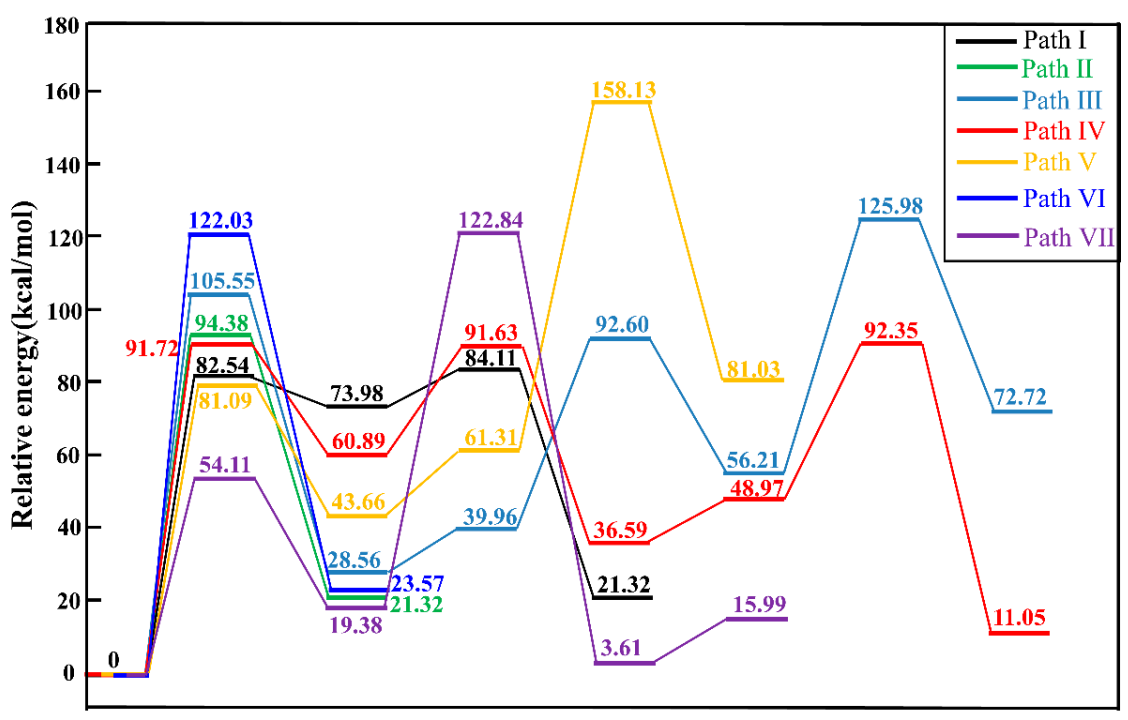

Figure 7. The potential energy diagram for the path I to path VII.

When the $\beta-C-C$ bond is broken, the rate-determining steps of the two reaction paths are both initial cleavage reactions. The activation barrier of the L-R3 is $94.38 \mathrm{kcal} / \mathrm{mol}$, where is $11.84 \mathrm{kcal} / \mathrm{mol}$ 
higher than the activation barrier of the rate-determining step in the path I. Therefore, it is presumed that the reaction is divided into two steps when the $\beta-\mathrm{C}-\mathrm{C}$ bond is broken (L-R1 and L-R2).

As shown in Figure 7, it is obvious that the rate-determining step in the path III is reaction $\mathrm{L}-\mathrm{R} 4$ with the high activation barrier of $105.55 \mathrm{kcal} / \mathrm{mol}$. The activation barriers of reaction L-R 5 and reaction L-R6 are $52.64 \mathrm{kcal} / \mathrm{mol}$ and $69.77 \mathrm{kcal} / \mathrm{mol}$, respectively. It is available that intermediates of formaldehyde and methyl formate are formed in the Path III. Due to the relatively low activation barrier of the reaction L-R5 and reaction L-R6, methyl formate undergoes further decarbonylation reactions. The oxygen element is partially removed, and an oxygen-containing species with poor stability is finally generated. In the path IV, the activation barrier required for the initial cracking reaction is approximately $15 \mathrm{kcal} / \mathrm{mol}$ lower than that of the L-R4 reaction. The intermediate species Int4 has a relatively high single-point energy and is prone to further cracking reactions. Additionally, the decarboxylation reaction (L-R8) only requires an activation barrier of $30.74 \mathrm{kcal} / \mathrm{mol}$, which is relatively low in the cracking reaction over the Lewis acid. Moreover, the reaction L-R8 is exothermic, and the configuration of the product is stable. Then the two alkyl groups undergo the bonding reaction $\mathrm{L}-\mathrm{R} 9$ (activation barrier is $43.36 \mathrm{kcal} / \mathrm{mol}$ ). The path IV is dominant in the deoxygenation reaction of $\alpha-C-C$ bond breaking. It is an ideal deoxygenation cracking reaction path. Not only can completely remove oxygen, but it also ensures the maximum retention of hydrocarbons, rather than in the form of $\mathrm{CO}, \mathrm{H}_{2} \mathrm{O}$, aldehyde, or acid.

It can be clearly seen from the Figure 7 that the reactions in path VI are more difficult than the reactions in path $\mathrm{V}$. Path $\mathrm{V}$ ultimately produces formaldehyde, $\mathrm{CO}$, and propane. The activation barrier of L-R10 for $\alpha-\mathrm{C}-\mathrm{O}$ bond breaking is $81.09 \mathrm{kcal} / \mathrm{mol}$. The activation barrier required for the decarbonylation reaction (L-R11) is $96.82 \mathrm{kcal} / \mathrm{mol}$, which is $15.73 \mathrm{kcal} / \mathrm{mol}$ higher than that of the L-R10 reaction. Therefore, in this path, the intermediate species Int6 may no longer undergo the subsequent cracking reaction. The products generated in the path VI are methanol and butanone. The initial cracking products generated from the above two paths are stable molecules, and are difficult to occur the secondary cracking reaction. The above three elementary reactions contained in path $\mathrm{V}$ and path VI are all endothermic reactions and have high activation barriers. Therefore, it is considered that the cleavage of $\alpha-\mathrm{C}-\mathrm{O}$ is not prone to occur under the Lewis acid catalysis. Previous report indicated that fatty acid esters generated aldehydes, alcohols, ketenes, and other oxygen-containing substances on $\mathrm{Al}_{2} \mathrm{O}_{3}$ catalysts only with Lewis acid [15]. Moreover, a large number of experimental results showed that more $\mathrm{CO}_{2}$ was generated than $\mathrm{CO}$ over $\mathrm{Al}_{2} \mathrm{O}_{3}$ catalyst [13-15,33]. The above calculation results explain well some of the phenomena in the experiments.

The potential energy diagram in Figure 7 shows that the activation barrier required for the L-R13 reaction is $54.11 \mathrm{kcal} / \mathrm{mol}$, which is relatively low. Compared to the other initial cracking reactions, the activation barrier required for $\beta-\mathrm{C}-\mathrm{O}$ bond cleavage is the lowest. However, the activation barrier required for the decarboxylation reaction (L-R14) is almost twice that of the L-R13 reaction. In the path VII, the catalytic cracking deoxygenation reaction generates butane and $\mathrm{CO}_{2}$, and the L-R14 reaction is the rate-determining step of the path.

\subsection{Discussion}

The activation barrier of the rate-determining steps and product structures of each reaction path are summarized in a petal-shaped diagram, as shown in Figure 8. Each petal represents a reaction path. $E a$ and the structure diagram respectively represent the activation barrier and product configuration corresponding to different reaction path. When the $\beta-\mathrm{C}-\mathrm{C}$ bond is broken, the bond breaking reaction occurs first and then the hydrogen transfer reaction occurs. Path I crosses the activation barrier of 82.54 $\mathrm{kcal} / \mathrm{mol}$ to generate an ethylene and a methyl acetate. Path III and path IV are paths of the $\alpha-\mathrm{C}-\mathrm{C}$ bond cracking reaction. The activation barrier required for each elementary reaction in path IV is lower than that required for path III. In other words, $\mathrm{CO}_{2}$ and butane are more easily formed in the $\alpha-\mathrm{C}-\mathrm{C}$ bond cracking. In the cracking of $\alpha-\mathrm{C}-\mathrm{O}$ bond, there are also two paths, and a formaldehyde and a butyraldehyde are generated because the activation barrier of the elementary reaction of path $\mathrm{V}$ 
is much lower than the activation barrier of the elementary reaction of path VI. However, a higher activation barrier is required for the subsequent deoxygenation of butyraldehyde. Thus, the aldehyde is formed rather than the hydrocarbon molecules. When the $\beta-\mathrm{C}-\mathrm{O}$ bond is broken, the products are $\mathrm{CO}_{2}$ and butane. Although the activation barrier required for initial cleavage of path VII is much lower than the activation barrier for other initial cracking reactions, the rate-determined step is $\mathrm{L}-\mathrm{R} 14$ and the activation barrier is as high as $103.46 \mathrm{kcal} / \mathrm{mol}$. Combined with energy analysis, the optimal cracking path of methyl butyrate on the Lewis acid site is $\mathrm{CH}_{3} \mathrm{CH}_{2} \mathrm{CH}_{2} \mathrm{C}\left(\mathrm{OCH}_{3}\right)=\mathrm{O} \cdots$ Lewis $\rightarrow \mathrm{CH}_{3} \mathrm{CH}_{2} \cdots$ Lewis $\cdots \mathrm{C}\left(=\mathrm{CH}_{2}\right) \mathrm{OCH}_{3} \rightarrow \mathrm{CH}_{2}=\mathrm{CH}_{2}+\mathrm{CH}_{3} \mathrm{COOCH}_{3}+$ Lewis (path I). The oxygen element is mainly removed in the form of $\mathrm{CO}_{2}$. It is consistent with the conclusion obtained by $\mathrm{Li}$ et al. that the main reaction path of fatty acid esters on alumina is decarboxylation reaction step [34]. The path IV generates butane and $\mathrm{CO}_{2}$, which can maximize the utilization of the hydrocarbon elements in fatty acid esters.

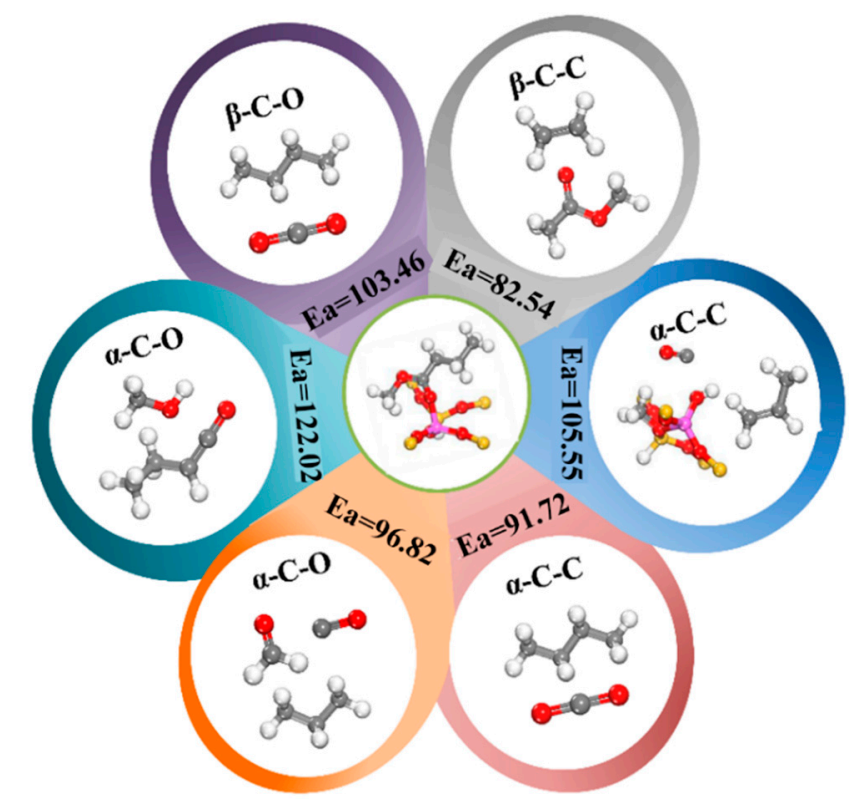

Figure 8. Summary diagram of the reaction path of methyl butyrate on the Lewis acid of ZSM-5 zeolite.

It also can be concluded that the difficulty of breaking the bond increases in the order of $\alpha-\mathrm{C}-\mathrm{C}$ bond, $\beta-\mathrm{C}-\mathrm{C}$ bond, $\alpha-\mathrm{C}-\mathrm{O}$ bond, and $\beta-\mathrm{C}-\mathrm{O}$ bond in the catalytic conversion of methyl butyrate on a Lewis acid. During the initial cleavages, the configuration transition of the Lewis acid center and the Brønsted acid center can greatly reduce the activation barrier required for the initial cracking reaction. In addition, the single point energies of the products obtained by above way are high. The intermediate species, for example, Int1, Int4, and Int7 have poor stability and are more prone to further occur deoxygenation reactions. In the subsequent reaction, the oxygen element is mainly removed in the form of $\mathrm{CO}_{2}$ and oxygen-containing derivatives such as methyl acetate, formaldehyde, and butyraldehyde. The hydrocarbon species mainly include ethylene, propylene, and butane. However, in our previous research, it is found that the methyl butyrate tends to break at the $\mathrm{C}-\mathrm{O}$ bond under the catalysis of Brønsted acid [11]. The initial pyrolysis product contains butyric acid, butyryl cation, and methanol. Then, the initial cracked products further react through dehydration and decarbonylation to form alkyl alkoxides. The oxygen element is mainly removed in the form of $\mathrm{CO}$ and $\mathrm{H}_{2} \mathrm{O}$.

Obviously, the activation barriers required for the catalytic reactions on Lewis acid are higher than that on Brønsted acid [11,12]. Numerous studies in the experiment also show that Brønsted acid plays a key role in the cleavage of fatty acid esters [8,15,35-37]. Taking the research of Li et al. as an example, under the catalytic conditions of catalysts with different acid sites, the catalyst with Brønsted acid exhibits outstanding catalytic effects in both conversion rate and deoxidation capacity [35]. As in the experiment conducted by Thanh et al. $[8,15]$, the catalyzed reaction temperature of Lewis acid is 
significantly higher than the catalyzed reaction temperature of Brønsted acid. At the same temperature, the content of oxygen species in the liquid phase under alumina catalysis is higher than that under zeolite catalysis [37]. The fact that the high activation barrier of the reaction on alumina catalysis resulting in oxygen cannot be completely removed is confirmed. However, studies have shown that excessive oxygen-containing species (aldehydes, ketones, acids, etc.) in the catalytic cracking process can cause foaming in equipment such as liquefied gas desulfurization and gasoline alkaline washing, as well as problems of substandard sewage discharge. In addition, it is difficult to remove, which seriously affects the normal production of the device [38]. In the design of the catalyst, the Brønsted acid strength and Brønsted acid content should be enhanced to improve the removal of oxygen element.

\section{Model and Methods}

\subsection{Model}

$\mathrm{Al}$ in the silica-alumina zeolite is divided into framework aluminum and non-framework aluminum. Framework aluminum includes tetracoordinated aluminum providing a Brønsted acid and tricoordinated aluminum providing a Lewis acid. The non-framework aluminum is mainly in the form of particles such as $\mathrm{AlO}^{+}, \mathrm{Al}(\mathrm{OH})_{2}{ }^{+}, \mathrm{Al}(\mathrm{OH})_{2}{ }^{+}, \mathrm{AlOOH}$, and $\mathrm{Al}_{2} \mathrm{O}_{3}$, which are distributed in various channels and pores to provide Lewis acids for catalytic reactions [39]. Extensive studies have suggested that it is reasonable to represent a Lewis acid with a tricoordinated framework aluminum [40-44]. The calculation results in which the tricoordinated framework $\mathrm{Al}$ was used to indicate the Lewis acid site of a zeolite are consistent with the shifts obtained from the spectra $[40,41]$. According to previous work, methyl butyrate can be stably adsorbed at the intersections of straight channels and sinusoidal channels [11]. Therefore, the $32 \mathrm{~T}$ cluster model was selected in this work. As shown in the Figure 9, the T12 atom is a tricoordinated Al. The channel corresponding to Figure 9(a) is a sinusoidal channel, and the channel corresponding to Figure $9(\mathrm{~b})$ is a straight channel. The $\mathrm{Al}$ atom forms a regular plane triangle configuration with the surrounding three oxygen atoms, which causes the channel structure to distort and the diameter of the channel to decrease.

(a)

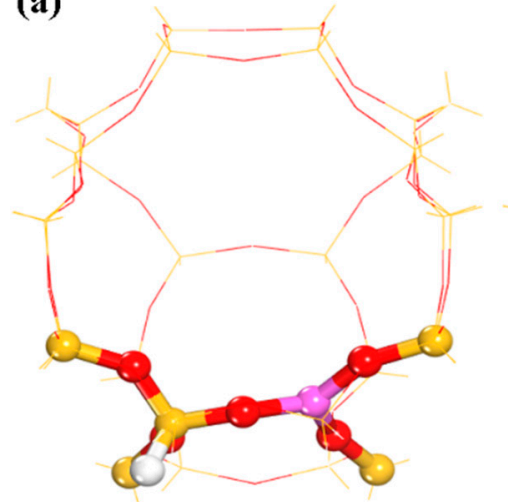

(b)

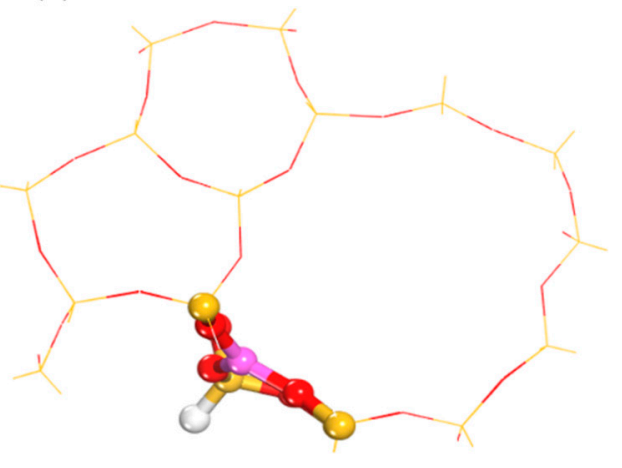

Figure 9. $32 \mathrm{~T}$ cluster model of a Lewis acid in the HZSM-5 zeolite. (a) Sinusoidal channel and (b) straight channel.

To verify the rationality of the model construction, the $\mathrm{CO}$ properties adsorbed on the model were further calculated. As shown in Table 2, the structural parameters of the adsorbed configuration agree with the result obtained by Benco [45]. The differences are all within the range of $0.02 \AA$. 
Table 2. Structural parameters of CO adsorbed on the $32 \mathrm{~T}$ cluster of the HZSM-5 zeolite.

\begin{tabular}{|c|c|c|c|c|}
\hline \multirow{2}{*}{ Model } & \multicolumn{2}{|c|}{ C-O Distance $(\AA ̊)$} & \multicolumn{2}{|c|}{ X-Y a Distance $(\AA ̊)$} \\
\hline & $-\mathrm{CO}$ & $-\mathrm{OC}$ & $-\mathrm{CO}$ & $-\mathrm{OC}$ \\
\hline $32 \mathrm{~T}$ cluster in this paper & 1.121 & 1.137 & 2.183 & 2.209 \\
\hline Model in literature [37] & 1.135 & 1.146 & 2.173 & 2.200 \\
\hline
\end{tabular}

\subsection{Methods}

The calculation results of the work were completed by the $\mathrm{Dmol}^{3}$ module in Materials Studio 8.0 software. The m-GGA (M06-L) functional was used to describe the exchange-related energy. Compared with the widely used B3LYP functional, the m-GGA functional shows unique computational advantages in determining thermodynamics, kinetics, noncovalent interactions, bond length, activation energy barrier, and vibration frequency [46]. In addition, in the parameterized M06-L functional, the midrange dispersion interaction is considered, resulting in an average unsigned error of less than $2 \mathrm{kcal} / \mathrm{mol}$ [46-48]. The basis set was a double-valued plus polarization (DNP). The transition state search used the complete LST/QST method [49]. The vibration distribution function and zero-point energy (ZPE) were obtained by frequency calculations, and all the energies were corrected by the zero-point value. The precision was fine, and the corresponding convergence standards of energy, gradient, and displacement were $1.0 \times 10^{-5} \mathrm{Ha}, 0.02 \mathrm{Ha} / \mathrm{nm}$ and $0.005 \AA$, respectively. A smearing value of $0.005 \mathrm{Ha}$ was used to increase the speed of convergence.

The calculation of the adsorption energy (Eads) is shown in formula (1). Eads, $E_{M B+z e o l i t e}, E_{z e o l i t e}$, and $E_{M B}$ represent the adsorption energy of methyl butyrate, the total energy of methyl butyrate adsorbed on the $32 \mathrm{~T}$ cluster model, the energy of the $32 \mathrm{~T}$ cluster model, and the energy of methyl butyrate, respectively.

$$
E_{\text {ads }}=E_{M B+z e o l i t e}-E_{\text {zeolite }}-E_{M B}
$$

\section{Conclusions}

Multiple reaction paths under the condition of Lewis acid catalysis were designed according to the breaking of different bonds. The calculation and analysis of thermodynamic parameters show that the initial cleavage of methyl butyrate is more likely to occur at the $\mathrm{C}-\mathrm{C}$ bond under the Lewis acid. In the path $\mathrm{I}$, the initial cracking activation energy barrier is low, and the subsequent cracking reaction exhibits spontaneity. Therefore, $\mathrm{CH}_{3} \mathrm{CH}_{2} \mathrm{CH}_{2} \mathrm{C}\left(\mathrm{OCH}_{3}\right)=\mathrm{O} \cdots$ Lewis $\rightarrow \mathrm{CH}_{3} \mathrm{CH}_{2} \cdots$ Lewis $\cdots \mathrm{C}\left(=\mathrm{CH}_{2}\right) \mathrm{OCH}_{3} \rightarrow$ $\mathrm{CH}_{2}=\mathrm{CH}_{2}+\mathrm{CH}_{3} \mathrm{COOCH}_{3}+$ Lewis (path I) is considered as the optimal reaction path.

By comparing the cleavage mechanism of Brønsted acid and Lewis acid, methyl butyrate is more likely to break the $\mathrm{C}-\mathrm{O}$ bond under the Brønsted acid, and the $\mathrm{O}$ element is removed in the form of $\mathrm{H}_{2} \mathrm{O}$ and $\mathrm{CO}$. However, $\mathrm{C}-\mathrm{C}$ bond cleavage is more likely to occur under Lewis acid catalysis, and $\mathrm{O}$ element is removed in the form of $\mathrm{CO}_{2}$. The activation barrier of each elementary reaction in the Brønsted acid cleavage mechanism is lower than that of the Lewis acid. Therefore, the Brønsted acid plays an important role in the catalytic cracking reaction of ZSM-5 zeolite.

Author Contributions: X.C.: conceptualization, formal analysis, writing-original draft; R.L.: data curation, investigation, visualization; H.Y.: formal analysis, visualization; Y.L.: supervision, writing-review and editing; C.Y.: supervision, funding acquisition. All authors have read and agreed to the published version of the manuscript.

Funding: This work was funded by the Fundamental Research Funds for the Central Universities (20CX02210A) and the National Natural Science Foundation of China (21776312).

Conflicts of Interest: There are no conflicts to declare. 


\section{References}

1. Issariyakul, T.; Dalai, A.K. Biodiesel from vegetable oils. Renew. Sust. Energy Rev. 2014, 31, 446-471. [CrossRef]

2. Singh, D.; Sharma, D.; Soni, S.L.; Sharma, S.; Sharma, P.K.; Jhalani, A. A review on feedstocks, production processes, and yield for different generations of biodiesel. Fuel 2020, 262, 116553. [CrossRef]

3. Huber, G.W.; Corma, A. Synergies between bio- and oil refineries for the production of fuels from biomass. Angew. Chem. Int. Ed. 2007, 46, 7184-7201. [CrossRef] [PubMed]

4. Idem, R.O.; Katikaneni, S.P.; Bakhshi, N.N. Catalytic conversion of canola oil to fuels and chemicals over various cracking catalysts. Fuel Process. Technol. 1997, 51, 101-125. [CrossRef]

5. Wu, Q.; Wang, Y.; Peng, Y.; Ke, L.; Yang, Q.; Jiang, L.; Dai, L.; Liu, Y.; Ruan, R.; Xia, D.; et al. Microwave-assisted pyrolysis of waste cooking oil for hydrocarbon bio-oil over metal oxides and HZSM-5 catalysts. Energy Conv. Manag. 2020, 220, 113124. [CrossRef]

6. Atsushi,I.; Takashi, T.; Tadanori,H.; Hiroyuki, N. Catalytic cracking of soybean oil by ZSM-5 zeolite-containing silica-aluminas with three layered micro-meso-meso-structure. Catal. Today 2018, 303, 123-129. [CrossRef]

7. Wang, J.; Zhong, Z.; Ding, K.; Zhang, B.; Deng, A.; Min, M.; Chen, P.; Ruan, R. Successive desilication and dealumination of HZSM-5 in catalytic conversion of waste cooking oil to produce aromatics. Energy Conv. Manag. 2017, 147, 100-107. [CrossRef]

8. Phung, T.K.; Casazza, A.A.; Finocchio, E.; Busca, G. Catalytic conversion of ethyl acetate over faujasite zeolites. Appl. Catal. A Gen. 2014, 470, 72-80. [CrossRef]

9. Cai, W.; Yan, H.; Feng, X.; Liu, Y.; Yang, C. Product distribution in catalytic cracking of fatty acid methyl esters with different carbon chain lengths. CIESC J. 2017, 68, 2057-2065. [CrossRef]

10. Botas, J.A.; Serrano, D.P.; García, A.; Ramos, R. Catalytic conversion of rapeseed oil for the production of raw chemicals, fuels and carbon nanotubes over Ni-modified nanocrystalline and hierarchical ZSM-5. Appl. Catal. $B$ Environ. 2014, 145, 205-215. [CrossRef]

11. Li, R.; Yan, H.; Dang, Y.; Liu, Y.; Feng, X.; Chen, X.; Jin, X.; Yang, C. Deoxygenation mechanism of methyl butyrate on HZSM-5: A density functional theory study. Mol. Catal. 2019, 479, 7-26. [CrossRef]

12. Yan, H.; Feng, X.; Liu, Y.; Yang, C.; Shan, H. Catalytic cracking of acetic acid and its ketene intermediate over HZSM-5 catalyst: A density functional theory study. Mol. Catal. 2017, 437, 11-17. [CrossRef]

13. Vonghia, E.; Boocock, D.G.B.; Konar, S.K.; Leung, A. Pathways for the deoxygenation of triglycerides to aliphatic hydrocarbons over activated alumina. Energy Fuel 1995, 9, 1090-1096. [CrossRef]

14. Leung, A.; Boocock, D.G.B.; Konar, S.K. Pathway for the catalytic conversion of carboxylic acids to hydrocarbons over activated alumina. Energy Fuel 1995, 9, 913-920. [CrossRef]

15. Phung, T.K.; Casazza, A.A.; Aliakbarian, B.; Finocchio, E.; Perego, P.; Busca, G. Catalytic conversion of ethyl acetate and acetic acid on alumina as models of vegetable oils conversion to biofuels. Chem. Eng. J. 2013, 215, 838-848. [CrossRef]

16. Blaszkowski, S.R.; Nascimento, M.A.C.; van Santen, R.A. Activation of C-H and C-C Bonds by an Acidic Zeolite: A Density Functional Study. J. Phys. Chem. 1996, 100, 3463-3472. [CrossRef]

17. Kolganov, A.A.; Gabrienko, A.A.; Yashnik, S.A.; Pidko, E.A.; Stepanov, A.G. Nature of the surface intermediates formed from methane on Cu-ZSM-5 zeolite: A combined solid-state nuclear magnetic resonance and density functional theory study. J. Phys. Chem. C 2020, 124, 6242-6252. [CrossRef]

18. Goncalves, T.J.; Plessow, P.N.; Studt, F. On the accuracy of density functional theory in zeolite catalysis. ChemCatChem 2019, 11, 4368-4376. [CrossRef]

19. Liu, Y.; Dang, Y.; Feng, X.; Chen, X.; Yang, C. Promoting effect of Ni on the structure and electronic properties of $\mathrm{Ni}_{\mathrm{x}} \mathrm{Mo}_{(1-\mathrm{x})} \mathrm{S}_{2}$ catalyst and benzene adsorption: A periodic DFT study. Appl. Surf. Sci. 2019, 471, 607-614. [CrossRef]

20. Rangarajan, S.; Mavrikakis, M. DFT insights into the competitive adsorption of sulfur- and nitrogen-containing compounds and hydrocarbons on Co-promoted molybdenum sulfide catalysts. ACS Cat. 2016, 6, 2904-2917. [CrossRef]

21. Rubes, M.; Trachta, M.; Koudelková, E.; Bulánek, R.; Kasneryk, V.; Bludský, O. Methane adsorption in ADOR zeolites: A combined experimental and DFT/CC study. Phys. Chem. Chem. Phys. 2017, 19, 16533-16540. [CrossRef] 
22. Fischer, M.; Bell, R.G. Modeling CO2 Adsorption in Zeolites Using DFT-Derived Charges: Comparing System-Specific and Generic Models. J. Phys. Chem. C 2013, 117, 24446-24454. [CrossRef]

23. Hessou, E.P.; Ponce-Vargas, M.; Mensah, J.-B.; Tielens, F.; Santos, J.C.; Badawi, M. Dibenzyl Disulfide Adsorption on Cationic Exchanged Faujasites: A DFT Study. Nanomaterials 2019, 9, 715. [CrossRef] [PubMed]

24. Huynh, L.K.; Violi, A. Thermal decomposition of methyl butanoate: Ab initio study of a biodiesel fuel surrogate. J. Org. Chem. 2008, 73, 94-101. [CrossRef] [PubMed]

25. Ali, M.A.; Violi, A. Reaction pathways for the thermal decomposition of methyl butanoate. J. Org. Chem. 2013, 78, 5898-5908. [CrossRef]

26. Chukwu, K.C.; Árnadóttir, L. Density functional theory study of decarboxylation and decarbonylation of acetic acid on Pd(111). J. Phys. Chem. C 2020, 124, 13082-13093. [CrossRef]

27. Banerjee, A.; Mushrif, S.H. Reaction pathways for the deoxygenation of biomass-pyrolysis-derived bio-oil on Ru: A DFT study using furfural as a model compound. ChemCatChem 2017, 9, 2828-2838. [CrossRef]

28. Baur, W.H.; Fischer, R.X. The floppiness of it all: Bond lengths change with atomic displacement Parameters and the flexibility of various coordination tetrahedra in zeolitic frameworks. An empirical structural study of bond lengths and sngles. Chem. Mater. 2019, 31, 2401-2420. [CrossRef]

29. Liang, M.; Zhu, X.; Ma, W. The propylene oxide rearrangement catalyzed by the Lewis acid sites of ZSM-5 catalyst with controllable surface acidity. Catal. Lett. 2019, 149, 942-949. [CrossRef]

30. Boronat, M.; Viruela, P.; Corma, A. Theoretical study on the mechanism of the hydride transfer reaction between alkanes and alkylcarbenium ions. J. Phys. Chem. B 1997, 101, 10069-10074. [CrossRef]

31. Haw, J.F. Zeolite acid strength and reaction mechanisms in catalysis. Phys. Chem. Chem. Phys. 2002, 4, 5431-5441. [CrossRef]

32. Stepanov, A.H.; Zamaraev, K.I. ${ }^{13} \mathrm{C}$ solid state NMR evidence for the existence of isobutyl carbenium ion in the reaction of isobutyl alcohol dehydration in H-ZSM-5 zeolite. Catal. Lett. 1993, 19, 153-158. [CrossRef]

33. Zheng, Z.; Lei, T.; Wang, J.; Wei, Y.; Liu, X.; Yu, F.; Ji, J. Catalytic cracking of soybean oil for biofuel over $\gamma-\mathrm{Al}_{2} \mathrm{O}_{3} / \mathrm{CaO}$ composite catalyst. J. Braz. Chem. Soc. 2019, 30, 359-370. [CrossRef]

34. Senol, O.I.; Viljava, T.R.; Krause, A.O.I. Hydrodeoxygenation of methyl esters on sulphided NiMo/ $\gamma-\mathrm{Al} 2 \mathrm{O} 3$ and CoMo $/ \gamma-\mathrm{Al} 2 \mathrm{O} 3$ catalysts. Catal. Today 2005, 100, 331-335. [CrossRef]

35. Katikaneni, S.P.R.; Adjaye, J.D.; Bakhshi, N.N. Performance of Aluminophosphate Molecular Sieve Catalysts for the Production of Hydrocarbons from Wood-Derived and Vegetable Oils. Energy Fuel 1995, 9, 1065-1078. [CrossRef]

36. Katikaneni, S.P.R.; Adjaye, J.D.; Bakhshi, N.N. Studies on the Catalytic Conversion of Canola Oil to Hydrocarbons: Influence of Hybrid Catalysts and Steam. Energy Fuels 1995, 9, 599-609. [CrossRef]

37. Katikaneni, S.P.R.; Adjaye, J.D.; Bakhshi, N.N. Catalytic conversion of canola oil to fuels and chemicals over various cracking catalysts. Can. J. Chem. Eng. 2010, 73, 484-497. [CrossRef]

38. Tian, H.; Chunyi, L.; Yang, C.; Shan, H. Alternative Processing Technology for Converting Vegetable Oils and Animal Fats to Clean Fuels and Light Olefins. Chin. J. Chem. Eng. 2008, 16, 394-400. [CrossRef]

39. Mota, C.J.; Bhering, D.L.; Rosenbach, N., Jr. A DFT study of the acidity of ultrastable Y zeolite: Where is the Bronsted/Lewis acid synergism? Angew. Chem. Int. Ed. 2004, 43, 3050-3053. [CrossRef]

40. Bucko, T.; Hafner, J.; Benco, L. Adsorption and vibrational spectroscopy of ammonia at mordenite: Ab initio study. J. Chem. Phys. 2004, 120, 10263-10277. [CrossRef]

41. Bucko, T.; Hafner, J.; Benco, L. Adsorption and vibrational spectroscopy of CO on mordenite: Ab initio density-functional study. J. Phys. Chem. B 2005, 109, 7345-7357. [CrossRef]

42. Sokol, A.A.; Catlow, C.R.A.; Garcés, J.M.; Kuperman, A. Computational investigation into the origins of Lewis acidity in zeolites. Adv. Mater. 2000, 12, 1801-1805. [CrossRef]

43. van Bokhoven, J.A.; van der Eerden, A.M.; Koningsberger, D.C. Three-coordinate aluminum in zeolites observed with in situ x-ray absorption near-edge spectroscopy at the Al K-edge: Flexibility of aluminum coordinations in zeolites. J. Am. Chem. Soc. 2003, 125, 7435-7442. [CrossRef] [PubMed]

44. Hernandez-Tamargo, C.E.; Roldan, A.; de Leeuw, N.H. Density functional theory study of the zeolite-mediated tautomerization of phenol and catechol. Mol. Catal. 2017, 433, 334-345. [CrossRef]

45. Benco, L.; Bucko, T.; Hafner, J.; Toulhoat, H. Ab initio simulation of Lewis sites in mordenite and comparative study of the strength of active sites via CO adsorption. J. Phys. Chem. B 2004, 108, 13656-13666. [CrossRef]

46. Zhao, Y.; Truhlar, D.G. A new local density functional for main-group thermochemistry, transition metal bonding, thermochemical kinetics, and noncovalent interactions. J. Chem. Phys. 2006, 125, 194101. [CrossRef] 
47. Zhao, Y.; Truhlar, D.G. Applications and validations of the Minnesota density functionals. Chem. Phys. Lett. 2011, 502, 1-13. [CrossRef]

48. Zhao, Y.; Ng, H.T.; Hanson, E. Benchmark data for noncovalent interactions in HCOOH...benzene complexes and their use for validation of density functionals. J. Chem. Theory Comput. 2009, 5, 2726-2733. [CrossRef]

49. Halgren, T.A.; Lipscomb, W.N. The synchronous-transit method for determining reaction pathways and locating molecular transition states. Chem. Phys. Lett. 1977, 49, 225-232. [CrossRef]

Publisher's Note: MDPI stays neutral with regard to jurisdictional claims in published maps and institutional affiliations.

(C) 2020 by the authors. Licensee MDPI, Basel, Switzerland. This article is an open access article distributed under the terms and conditions of the Creative Commons Attribution (CC BY) license (http://creativecommons.org/licenses/by/4.0/). 